\title{
OPTIMAL VERSUS REQUIRED DEFENCE EXPENDITURE: THE CASE OF THE GREEK-TURKISH ARMS RACE
}

\author{
A. S. ANDREOU ${ }^{\mathrm{a}, *}$, K. E. PARSOPOULOS ${ }^{\mathrm{b}}$, M. N. VRAHATIS ${ }^{\mathrm{b}, \dagger}$ and \\ G. A. ZOMBANAKIS ${ }^{\mathrm{c},}$ : \\ ${ }^{a}$ Department of Computer Science, University of Cyprus, 75 Kallipoleos str., P.O. Box 20537, \\ CY1678 Nicosia, Cyprus; ${ }^{\mathrm{b}}$ Department of Mathematics, University of Patras, Patras 26500, Greece; \\ ${ }^{\mathrm{c}}$ Research Department, Bank of Greece, 21 Panepistimiou street, Athens 102-50, Greece
}

(Received 15 August 2001; Revised 19 February 2002; In final form 7 March 2002)

\begin{abstract}
The aim of this paper is to indicate the extent to which the arms race against Turkey, in which Greece and Cyprus have been entangled, imposes a defence expenditure burden that is tough for the two allies to bear. To do so we have resorted to evaluating the optimal military expenditure for the two countries, allied in the context of the Integrated Defence Doctrine, which is compatible with the constraints imposed by the resources of their economies. All experiments and scenarios examined lead to the conclusion that the current defence burden of the two allies seems to be driving their economies beyond capacity limits. The fact remains, however, that under the circumstances, a one-sided disarmament policy like the one currently followed by Greece, is a risky choice given that the long-term armament programmes pursued by Turkey, whose role in this arms race has been proven as leading, leave very small room to the Greek and Cypriot sides to reduce their own defence expenditure.
\end{abstract}

Keywords: Optimal control; Defence expenditure; Arms race; Relative military security

JEL codes: C61, H56

\section{INTRODUCTION}

The recent rescheduling of the Turkish long-term defence procurement programmes following the economic crisis in the country and the reaction of the Greek authorities to reduce their own by about $25 \%$ have become the subject of extensive discussions. The issues involved in such discussions concern the possibility of a causal relationship between the developments in the two countries and the extent to which the two sides entangled, for ages now, in an expensive arms race, can afford a reduction of their defence expenditure. This leads to the next question, which involves the calculation of an "optimal" defence burden providing for maximum security in the face of an outside threat, bounded by the constraints imposed by

* Tel.: +357-2-892230; Fax: +357-2-339062; E-mail: aandreou@ucy.ac.cy

$\dagger$ Tel.: + 61-997374; Fax: +61-992965; E-mail: vrahatis@math.upatras.gr

* Corresponding author. Tel.: +1-3235809; Fax: +1-3233025; E-mail: gzombanakis@bankofgreece.gr 
the economy. The optimisation will take into account the spillover effects enjoyed by Greece and Cyprus, especially after the implementation of the Integrated Defence Doctrine between these two allies. Finally, we shall consider the extent to which pursuing such an optimum leads to a substantial peace dividend. The answers will be provided in the context of an optimal control solution, using an Interior Penalty Function Method, with Steepest Descent and Armijo Line Search, as explained in the Appendix, after a brief literature overview has been provided in section 2 . The third part of this paper includes the description of the econometric model used by the algorithm as a constraint structure under which the penalty function is minimised. Section 4 includes various policy considerations based on the results derived by the algorithm, while the conclusions drawn are stated in the last part of the paper.

\section{LITERATURE OVERVIEW}

The existence of an arms race between Greece and Turkey is a well established fact (Kollias and Makrydakis, 1997), determined, to a large extent, by demographic factors describing the Turkish rather than the Greek economic and demographic environment (Andreou and Zombanakis, 2000). The extent to which mutual reduction of defence expenditure would lead to a substantial peace dividend has been extensively analysed for both the Greek-Turkish case (Balfoussias and Stavrinos, 1996; Ozmucur, 1996; Kollias, 1997), as well in a more general context referring to the cost in terms of growth (Deger, 1986; Ward et al., 1991; Buck et al., 1993; Looney, 1994 and several authors in Hartley and Sandler 1990). In fact, the cost of an arms race, especially on the foreign sector of what is commonly termed a "small, open economy", is rather expensive since military expenditure is highly import-demanding, leading to foreign borrowing which exerts an adverse impact on both the domestic and the foreign sectors (Stavrinos and Zombanakis, 1998). Especially after the full implementation of the Integrated Defence Doctrine between Greece and Cyprus, the GDP shares of military expenditure by the two allies have exceeded $6 \%$ in certain cases, while the military debt of Greece in current U.S. dollars has doubled during the 1990s to reach more than 5 billion at the end of 2000, representing about $16 \%$ of the total General Government external debt of the country according to provisional Bank of Greece data. Kollias (1994; 1995 and 1996) and Antonakis (1996 and 1997) have investigated the economic effects of defence expenditure upon the Greek economy.

Defence expenditure constitutes a considerable burden for the economies of Greece and Cyprus, raising questions about the ideal defence burden. A convenient way to tackle such issues is using a constrained optimisation analysis which requires minimising the deviations of the endogenous variables of an economic system from their respective target values subject to the constraints imposed by the economy (e.g. Chow, 1975; Levy, 1992). The method thus leads to determining the ideal or optimal values for those variables, to the extent, of course, that these are attainable. It is important to stress that the derived values for defence expenditure shall be characterised as optimal in the strict economics sense without involving any constraints of strategic or tactical nature, an issue beyond the scope of this paper. The optimal control analysis, therefore, will specify the defence expenditure that the two allies are able to afford in the context of the theory of alliances in its simplest form (Hartley and Sandler, 1995).

\section{THE MODEL}

The constraint structure we use for the optimisation procedure is a small, highly aggregated model of seven equations representing the economies of Greece and Cyprus. The model is 
based on previous research (Stavrinos and Zombanakis, 1998), placing emphasis on the defence expenditure side, while variables expressing the Turkish side are taken as exogenous. The majority of the variables are expressed in terms of GDP percentages aiming at concentrating on the growth effects of the priorities assigned to defence policy. Such effects became more pronounced in cases like the Turkish invasion of Cyprus in 1974 and the Greek-Turkish crises in 1982 and 1987. As a first step, all the variables in the stochastic equations have been expressed in natural logs and tested for integration.

\subsection{The Demand for Defence Expenditure and the Security Function}

The demand for defence expenditure for each of the two allies, namely Greece and Cyprus, is represented as follows:

$$
\begin{aligned}
& \mathrm{GDEF}=f(\mathrm{GGDP}, \mathrm{GNDEF}, \mathrm{GBOP}, \mathrm{DRDL}, \mathrm{RS}, \mathrm{TDEF}) \\
& \mathrm{CDEF}=f(\mathrm{CGDP}, \mathrm{CNDEF}, \mathrm{CBOP}, \mathrm{DLCP}, \mathrm{RS}, \mathrm{TDEF})
\end{aligned}
$$

where GDEF and CDEF are the corresponding GDP shares of defence expenditure for the two allies. Military expenditure is usually reported in current prices in local currency terms. For most purposes of economic analysis, however, it is the share of military expenditure to GDP - the military burden - that is of most interest because it reflects the relative priority given by the state to military demands and because it measures the relative burden or resource costs. ${ }^{1}$ Its calculation does not depend on the choice of a specific price index, since it is the ratio of two measures in current domestic currency. It is a pure number that can be compared over time and across countries and it is by now extensively used in empirical investigations. There is, however, caution expressed in the literature since measuring the military spending and the other variables in the model as shares or proportions of GDP can be misleading and may introduce biases in the measurement of certain coefficients (Chan, 1985). Assuming inflation rates roughly equal for defence and non-defence activities, omitting the price variable does not introduce any biasing results. ${ }^{2}$ GGDP and CGDP are the Greek and Cypriot GDP at constant prices, respectively; GNDEF and CNDEF represent the share of non-defence expenditure in the GDP of the two countries; GBOP and CBOP represent the Greek and Cypriot balance-of-payments deficits as a share in their respective GDP, while DRDL and DLCP stand for the two countries respective currency rates against the US dollar. Notice that the price variable is not included in these functions, due to the lack of import substitution in the two countries, a problem which renders the demand for defence equipment almost completely price inelastic. The threat variable in both cases is TDEF, which represents the share of defence expenditure in the Turkish GDP. Finally, special attention should be drawn to the spillover variable. One might be tempted to argue that a suitable spillover variable would be the military burden of the NATO countries except Greece and Turkey. We feel, however, that since our aim is to concentrate on the Greek-Cypriot alliance as this is expressed through the Integrated Defence Doctrine, what is required is an alternative measure tailored to fit this particular case. We have chosen, therefore, to use a measure of relative security as a result of the two countries' alliance. This is applicable to cases in which the role of the substantial difference in human resources endowments between the two sides

\footnotetext{
${ }^{1}$ See Goertz and Diehl (1986), and Herrera (1994), for the comparison of different approaches in measuring military allocations.

${ }^{2}$ See Hartley and Sandler (1995) p. 61. Data on prices of Greek and Cypriot defence equipment - usually importables - is not available. To the extent that such imports are reported in the balance of payments, import prices of the appropriate SITC category do not exhibit significant differences compared to the rest of the categories.
} 
involved in an arms race is decisive (Andreou and Zombanakis, 2001). The measure of this relative security coefficient is given by: ${ }^{3}$

$$
\mathrm{RS}=\exp [x]
$$

where $x$ stands for the ratio of the difference between the Greek and Cypriot population rates of change over the corresponding Turkish figure, as follows:

$$
x=\frac{\left(\dot{p}_{G}-\dot{p}_{C}\right)}{\dot{p}_{T}}
$$

On the basis of (3) and (4) one may be tempted to argue that the ideal alliance target for a balance between the two sides concerning security would be a value of $\mathrm{RS}=2.718$, once $x$ assumes the value of unity. Under the circumstances, however, this is a prohibitive restriction, meaning that the applied side of the matter calls for a more realistic constraint. It must be borne in mind, however, that this relative security coefficient composed of the population characteristics of the two sides involved in an arms race includes more than meets the eye. In fact, the role of the population rates of increase in the RS is not only associated with the possibilities to increase manpower in the armed forces, something which does not necessarily agree with the concepts of modern warfare tactics. It is also linked with the continuous and pressing demands of Turkey for increase of its vital space justified by the population explosion in the country. We feel, therefore, that, given the particularity of the Greek-Turkish arms race, which is affected to a large extent by population developments in the countries involved, the RS identity can serve as a security function entering the allies' utility function. ${ }^{4}$

\subsection{The Output Equation}

The GDP in the two countries is determined on the basis of a behavioural equation rather than an identity, given that the optimisation procedure requires that emphasis is placed on the shares of the various GDP components in it. Equations (5) and (6) describe growth in the two allied countries in terms of its main ingredients: accumulation of physical capital as investment in Greece and Cyprus, GTI and CTI, respectively; non-defence expenditure; and net imports of goods and services as an indication of the external constraint imposed on the growth rate of the economy. Finally, the local currency exchange rate is included given that it has been a very popular policy instrument for the period under study. Thus, the GDP in both countries is taken to be determined as follows:

$$
\begin{aligned}
& \mathrm{GGDP}=f(\mathrm{GNDEF}, \mathrm{GTI}, \mathrm{GBOP}, \mathrm{DRDL}) \\
& \mathrm{CGDP}=f(\mathrm{CNDEF}, \mathrm{CTI}, \mathrm{GBOP}, \mathrm{DLCP})
\end{aligned}
$$

\footnotetext{
${ }^{3}$ The RS is a relative security measure particularly tailored to fit cases like the Greece/Cyprus conflict against Turkey. In cases like this the population rates of increase in the two sides play a leading role and this index is designed to emphasise on this specific point, as it is explained in the text. The target set for the RS in this optimisation procedure is that population developments on the Greek/Cypriot alliance side counterbalance the Turkish generous population rates of increase, a rather demanding target one must admit. If this is the case, then the numerator must equal the denominator of $x$ yielding a value of unity, the $\log$ of which is 2.718 . For a detailed explanation on this relative security measure, see Andreou and Zombanakis 2001.

${ }^{4}$ See, for example, Bruce (1990).
} 
where GTI and CTI stand for the GDP shares of total investment expenditure in Greece and Cyprus. It must be borne in mind that given the trade-off between non-defence and defence expenditure (Benoit, 1978), the latter can be thought of as implicitly introduced in these functions to account for the direct effects of military spending on growth in the form of spin-offs, either favourable or adverse (Hartley and Sandler, 1995). ${ }^{5}$ Thus, Eqs. (9) and (12) presented in the Appendix simply underline the importance of the various output components in the GDP of each country, as well as the leading role of the international exchange rate, a policy instrument traditionally used by the economies of the two allies.

\subsection{The Population Equation}

Since we have already underlined the importance of human resources in the Greek-Turkish conflict (Andreou and Zombanakis, 2000 and 2001), we have chosen to devote a behavioural equation to describe population developments in each of the two allies. ${ }^{6}$ Thus, the Greek and Cypriot populations are taken to behave as follows:

$$
\begin{aligned}
& \text { GPOP }=f(\text { GGDP }, \text { GDEF }, \text { GNDEF }, \text { GCPI }) \\
& \text { CPOP }=f(\mathrm{CGDP}, \mathrm{CDEF}, \mathrm{CNDEF}, \mathrm{CCPI})
\end{aligned}
$$

where GCPI and CCPI are the Greek and Cypriot consumer price indices. The estimated Eqs. (11) and (14) for the two allies described in the Appendix draw attention to the role of both non-defence expenditure and the consumer price index in determining population growth (Ehrlich and Lui, 1997). The consumer price index is included in the function in order to introduce the budget constraint imposed on low-income families that can not afford to contribute to the population growth.

\subsection{Comments on the Equation Estimates}

Equations (9) to (14) as listed in the Appendix and the relative security measure for the two allies given by the combination of (3) and (4) make up the constraint structure under which the optimisation exercise will be undertaken.

All series have been found to be I(1), that is, stationary in their first differences, on the basis of the ADF test, while the estimation period undertaken ranges between 1960 and 2000. The short-run estimates presented in the Appendix comprise an error-correction model, with all coefficients bearing the expected signs and accompanied by their $t$-values in parentheses, while the explanatory power of all six equations is satisfactory. Finally, given the length of the estimation period, the dummies used in the equations tackle the effects of crises between Greece and Turkey or the influence of exogenous disturbances of political or social nature that introduce structural changes in the economies of the two allies. ${ }^{7}$ Thus, DCDEMO is used to capture the dramatic change in the Cypriot population after the 1974 invasion while DGDEMO includes the exogenous disturbance of the Greek population after the massive inflow of refugees from Turkey during the mid-1960s and the substantial increase in the number of illegal immigrant workers mainly from Albania and Bulgaria during the beginning of the nineties. DGDEF and DCDEF are used to capture revisions in the

\footnotetext{
${ }^{5}$ General surveys of the effects of military expenditure on growth and development are given in Renner (1991), Isard and Anderton (1992), Pivetti (1992), Mintz and Stevenson (1995) and Ward et al. (1995), among others. For comprehensive bibliographies in English see Klein et al. (1995), and Hartley and Hooper (1990).

${ }^{6}$ For a very useful review on the subject we resorted to Ehrlich and Lui (1997).

${ }^{7}$ See Hartley and Sandler (1995) p. 61.
} 
long-run defence programmes of Greece and Cyprus or lump-sum purchases which are settled through bilateral agreements and are not reflected in the external accounts of the two countries. The procurement of the Type-209 submarines from HDW by the Greek Navy during the beginning of the 1970s, the so-called purchase of the century involving the procurement of a large number of Mirage fighters during the mid-1980s, its revision after the change of the Greek government at the beginning of the 1990s and the procurement of the S-300 antiaircraft missiles by Cyprus during the end of the nineties are typical examples. DGGDP and DCGDP represent the effects of certain exogenous disturbances on the economies of the two allies like the three devaluations of the drachma in 1983, 1985 and 1996 and the pressure upon the Cypriot economy after the 1974 shock. Finally, DDIC and DCINV capture the prolonged social and political instability in Greece and Cyprus caused by the dictatorial regime between 1967 and 1974.

All variables are expressed in terms of first differences with the RES terms indicating the residual item of the corresponding long-run version of each equation. The ADF tests for these terms along with selected diagnostics are also included in the Appendix.

\subsubsection{The Demand for Defence Expenditure}

The resulting estimated equations for Greece (Eq. 10) and Cyprus (Eq. 13) listed in the Appendix describe the picture of their alliance against Turkey along the lines indicated in the literature. The trade-off between defence and non-defence expenditure is underlined in the cases of both Greece and Cyprus while the spill and threat variables seem to be important determinants of their defence expenditure. Finally, the long time lag required for the income variable to affect military spending is expected given the long-term horizon of the various defence procurement programmes that represent a considerable part of military spending in the two allied countries. The income inelasticity of defence expenditure in both equations underlines one of the major issues that this paper points out, namely the necessity to adhere to the defence expenditure programmes undertaken. The negative sign of the balance of payments coefficient in both cases designates the external constraint imposed on the defence procurement programmes, a constraint reinforced by the exchange rate effect, the coefficient in all cases indicating an inelastic response of the defence expenditure to these variables. Attention is required when interpreting the difference in the sign of the exchange rate coefficient between the Greek and the Cypriot cases which is due to the inversion of the parity fraction in the case of Cyprus.

\subsubsection{The Output Equation}

Equations (9) and (12) represent the Greek and Cypriot output growth respectively in terms of their main components and the domestic currency exchange rate against the U.S. All estimates bear the expected sign and are statistically significant with a marginal exception in the case of the exchange rate in (9). This point, together with the low elasticity derived in both equations are related to the controversy associated with the effects of a domestic currency devaluation on the rate of growth (Zombanakis, 1998) while attention, once more, is drawn to the difference in the sign of the exchange rate coefficient between (9) and (12). The considerable time lag in the case of the external constraint in the Greek case is related to the lengthy time period involved between an external trade transaction and its settlement with the conversion of the foreign exchange proceeds or payments to domestic currency, given that foreign exchange restrictions apply for a major part of the estimation period. 


\subsubsection{The Population Equation}

The estimation of the two population Eqs. (11) and (14) has faced a number of difficulties mainly due to the poor data quality, especially in the case of Cyprus, in which the 1974 invasion has introduced a major disturbance in the population pattern of growth. All coefficients, however, are statistically significant and bear the expected sign. The constraint imposed on population growth due to the standard of living is approximated by the consumer price index the reaction to which turns out to be quite significant, but highly inelastic in both cases. Finally, devoting funds to non-defence activities seems to contribute to the population increase while this is not the case for defence expenditure, at least in the case of the equation for Greece. Introducing defence spending in the Cypriot version of the equation did not produce any meaningful results and was, consequently excluded.

\subsubsection{The Constrained Optimisation}

The description of the historical data on the basis of the model seems to be quite satisfactory following a dynamic simulation. Given this set of equations as a constraint structure, the optimization problem is formulated by requiring the minimization of a "welfare function" the arguments of which are the squared deviations of the endogenous variables from their respective targets. These targets are set in the context of a number of scenarios while the policy instruments used are the GDP shares of defence expenditure in the two allied countries. Given that the importance assigned to each of these endogenous variables may differ depending on each policy-maker's hierarchy ordering and priorities, we have decided to perform the constrained optimisation introducing these priorities in the welfare function in two different ways. The first is to assign equal weights to all endogenous variables introducing a cardinal hierarchy ordering in terms of determining a target value for each endogenous variable which reflects the emphasis placed on either property or human resources. The second is to allow this emphasis to be reflected in the weights rather than the target values of the endogenous variables, an approach which focuses on the ordinal aspect of the hierarchy ordering. While the equations above have been estimated for the period between 1960 and 2000, the optimization exercise concentrates on the last eleven years, namely 1990 to 2000, in order to avoid the adverse repercussions of a large number of structural reforms, mostly of political nature, affecting Greece and Cyprus during the previous three decades.

\section{POLICY CONSIDERATIONS}

The analysis that follows is based on prior work on the conflict between Greece and Turkey, pointing out the importance of human resources in the arms race between the two sides (Andreou and Zombanakis, 2000). This means that there are three possible strategies that may be followed concerning the emphasis placed on resources. Two strategies emphasise human or property resources alone and a third one, using both property and human resources simultaneously. Emphasis on human resources is described by setting the Greek population rate to increase by about $1.5 \%$ to $2 \%$, and the corresponding Cypriot figure to remain close to zero. This difference in the population growth rates of the two allies will thus be equal to the Turkish population growth rate, keeping the two conflicting sides in a balance according to the relative security criterion RS, a very ambitious target indeed! Emphasis on property resources, capital equipment in particular, is expressed by setting the GDP growth rates of the two allies to $5 \%$. All three strategies must then be compared to a neutral, "reference" 
strategy in the sense that it does not stress the importance of either property or human resources. Each of these strategies, in its turn, involves four possible scenarios as it is usually the case in a typical arms race examined via game theory, or in the context of the "prisoner's dilemma" (Majeski, 1984). We assign, therefore, increasing or decreasing future values to the GDP shares of defence expenditure of Greece and Cyprus on one hand and Turkey on another, ${ }^{8}$ thus referring to the following four scenarios, with the terms "reduction" and "escalation" suggesting a respective decrease or increase of the GDP share of defence expenditure of the country or countries involved: 1 (both sides escalate), 2 (Greece and Cyprus escalate and Turkey reduces), 3 (Turkey escalates and Greece and Cyprus reduce) and 4 (both sides reduce). ${ }^{9}$

\subsection{Arms Race: Both Sides Escalate (Scenario 1)}

In case that both conflicting sides (i.e. Greece and Cyprus on one hand and Turkey on another) pursue escalation tactics the average optimal Greek and Cypriot GDP share of defence expenditure stands at about $3.5 \%$ for the decade under consideration. This is a very reasonable figure to a large extent, although slightly higher, compared to the corresponding figures of most EU and NATO members. The fact remains, that this figure for the two allies reaches as high as $6.0 \%$ to $6.5 \%$ in certain cases, depending on the time profile of their armament programmes. It is interesting to point out that the optimal defence expenditure figure, as a percentage of GDP, is remarkably stable on the average at about $3.4 \%$ to $3.6 \%$ for both allies, irrespective of strategies chosen. However, the average alliance relative security, as this is measured by RS, for the period under consideration obtains its highest optimal value when preponderance of human resources alone is assumed. This means that maximising the GDP share of defence expenditure alone, by itself, is not the only recipe for security maximisation, especially in the case of the Greek-Turkish arms race, in which the role of human resources is leading.

The deviations of the optimal values derived by the algorithm from their respective actual observations are a further interesting point to observe. It is important to stress at this point that the values derived are "optimal" only from the economics point of view that is, compatible to the constraints imposed by the model. Such values, therefore, are expected to differ compared to the corresponding actual values which can be considered as "de facto optimal" since their choice involves, in addition, geopolitical and strategic criteria that do not enter our constraint structure. Thus, the difference between the two aims at pointing out the resources devoted to defence over and above what the constrained optimisation procedure indicates and may be regarded as the cost suffered as a result of the arms race in which Greece and Cyprus are involved against Turkey. The first point to make concerns the main issue, which is the GDP shares of defence expenditure for the two allies. It seems that the Greek economy exceeds the optimal defence burden by about $25 \%$ on the average irrespective of the strategy followed. The excess defence expenditure with respect to the suggested optimal in the Greek case reaches close to $30 \%$ on the average for the period under review, when emphasis is placed on property resources. This is to a large extent, expected since it reflects the high cost of transforming the defence mechanism from a manpower-intensive complex to a

\footnotetext{
${ }^{8}$ The choice of the defence expenditure as a share of the GDP rather than the level of the military expenditure itself is widely used in the literature and aims at introducing, to a certain extent at least, the question of sustainability of the defence burden by relating it to the total output of an economy.

${ }^{9}$ The one-sided reduction of defence expenditure by either side hardly reflects an arms race environment and is simply included to adopt the picture to the theoretical framework of a simple arms race environment. (e.g. Hartley and Sandler 1995).
} 
defence mechanism focusing on small numbered, efficient forces armed with very expensive modern equipment, given the constraint imposed by the Greek economy. On the contrary, average defence overspending is slightly higher than $10 \%$ in the case of Cyprus, for all strategies involved, indicating that the Cypriot GDP share of defence spending is close to its optimal level. The extent to which this is a policy option or, instead, a result of a supply constraint remains to be seen as a matter of further research. It is important to concentrate, finally on the security level as this is measured by RS and attained by employing various strategies, in the context of the arms race scenario. To begin with, it seems that in all cases and as a result of defence overspending, the average actual security performance considerably exceeds the optimal. This finding also suggests that in the context of the ongoing arms race, the optimal security level required for the alliance leaves a great deal to be desired if emphasis were placed on property, rather than human resources. In fact, given the heavy structural reform cost of transforming the forces of the alliance into efficient, small-scale, wellequipped units on one hand, and the constraint of the alliance economies on the other, the average optimal security performance of the alliance deviates from the corresponding actual figure considerably. This deviation may be considerably restricted if the strategy concentrates on human resources, which, however, happens to be the strong point of the Turkish side (Andreou and Zombanakis, 2001). Bearing, therefore, these considerations in mind, we feel that property resources must be awarded special attention despite the cost involved, simply because Greece and Cyprus are expected to suffer a considerable disadvantage in the field of human resources in the long run. This view seems to be shared by the Greek Ministry of Defence which has embarked on a long-term plan aiming at making the Greek armed forces strongly capital intensive by adopting the modern but expensive dogma which places emphasis on effectiveness through speed, flexibility and sophisticated equipment (Greek Ministry of Defence, 2000).

\subsection{Offensive Alliance Tactics: Greece and Cyprus Escalate while Turkey Reduces (Scenario 2)}

This scenario assumes offensive tactics on the part of the alliance, this driving the relative security factor RS to considerably higher levels compared to the arms race scenario previously analysed, particularly if emphasis is placed on property resources, while the average optimal GDP share of defence expenditure barely exceeds $3.5 \%$ for both allies. It is most interesting to observe with reference to the policy considerations, as these are derived on the basis of the "reference" strategy, that the optimal values derived for both the relative security factor and the GDP shares of defence expenditure for the two allies are identical to those derived according to the fourth scenario of mutual disarmament by both the allies and Turkey which we shall consider below. This means that the reduction of defence expenditure by the Turkish side is the decisive element that affects the decision of the allied side concerning its military spending and, consequently, the performance of the model in terms of optimal values. On the contrary, the extent to which the allies will move to disarmament policies or not plays no role whatsoever.

In cases of offensive tactics from the part of the alliance while, in parallel Turkey reduces its defence expenditure, the average optimal deviations from their corresponding actual for Greece are all of the order between $26 \%$ and $28 \%$, indicating no substantial difference between strategies in the case of Greece while the corresponding Cypriot figures range between $12 \%$ and $17 \%$. Turning, finally, to the relative security measure, and given the reducing policy of the Turkish side, the optimal relative security measure when preponderance is awarded to property resources is considerably close to the actual level attained by the alliance, a result more or less expected as shifting to capital rather than human resources seems to be part of the modern warfare strategy in view of the considerable decline in the Greek population rate, 
a feature of a large number of modern advanced economies. Attaining this specific target by placing emphasis on property resources is facilitated by the concurrent defence-reducing policy from the part of Turkey.

\subsection{Defensive Alliance Tactics: Greece and Cyprus Reduce while Turkey Escalates (Scenario 3)}

As expected, the relative security factor is lower in this case compared to the scenario previously analysed, as a result of the defence expenditure reduction from the part of the alliance in parallel to the offensive Turkish tactics. The average GDP shares of defence expenditure, which are suggested as optimal, however, are remarkably fixed at about $3.5 \%$ for both allies, with maximum figures not exceeding $6.5 \%$ for Greece and about $6.0 \%$ for Cyprus. This simply means that as long as Turkey follows offensive defence policies, the two allies do not have any room for defence expenditures reduction. It seems, indeed, that the mobilisation of both categories of resources still does not seem to contribute to better defence performance, meaning that the economies are already close to their optimal defence expenditure levels.

The outstanding role of Turkey in its arms race against Greece and Cyprus is indicated very clearly in the context of this scenario, as it has been the case in scenario 2 . To show this, one needs to resort once more to the "reference" strategy that reflects reality clearer than any of the others, since it is relieved of any form of emphasis on either resource category. We can thus observe that the optimal values suggested for the GDP shares of defence expenditure of both allies, as well as for the relative security factor RS are identical to those derived in the case of the first scenario, according to which both sides escalate. It is evident, therefore, once again that the role of Turkey in the arms race against Greece and Cyprus is to dictate the intensity of this race, leaving the opposite side no room to mitigate this influence.

Concerning deviations between actual and optimal values, the escalation of the Turkish defence activity accompanied by reducing tactics from the part of the alliance seems to lead to attaining optimal Greek defence expenditure figures which are inferior to the corresponding actual by about $23 \%$ to $27 \%$ on the average. The lowest deviation is observed in cases in which no particular emphasis is placed on either human or property resources, an outcome that seems natural considering the context of this scenario. The corresponding Cypriot figures, however, appear quite low, lower than $10 \%$ in certain cases, indicating that the GDP defence expenditure is possibly close to what the economy can take. As a result of the policy followed by the two allies, the superiority of the use of property resources is obvious in this case as well, in which the optimal value attained falls short with respect to the actual RS by only $23 \%$ against $40 \%$ to $50 \%$ of the remaining strategies tested.

\subsection{Mutual Disarmament Agreement: Both Sides Reduce (Scenario 4)}

No matter how unrealistic this scenario appears, one must consider it for the sake of a complete analysis. It seems natural that diverting resources away from defence expenditure to alternative, non-defence activities reduces the optimal values suggested by the algorithm for certain observations, even if the average optimal GDP shares of defence expenditure remain close to $3.5 \%$ for both allies. In fact, this is the only scenario examined thus far in which placing emphasis on both property and human resources allows the Greek economy to restrict the maximum annual defence burden to $5.5 \%$ instead of $6.5 \%$ which has been the case thus far. This should be regarded as a blessing given the absence of a Turkish threat, since it suggests that the economy is allowed to pursue its defence programme, with fewer resources devoted to it, as is stated by assumption. This, of course, allows for a considerable peace dividend for the Greek economy. Unfortunately, this does not seem to be the case for 
Cyprus which, even in this case, is compelled to devote to defence spending shares as high as $6.0 \%$ of its GDP. ${ }^{10}$ It is finally comforting to observe that, in an environment of mutual disarmament policies on the part of Greece and Cyprus on one hand and Turkey on the other, the relative security factor between the two allies can reach rather high values on certain occasions, particularly if property resources are mobilised.

From the point of view of deviations between actual and optimal values, the mutual reduction scenario appears to be the least costly, for the Greek side at least, when emphasis is placed on human resources, in the case of which the optimal value of the GDP share of defence expenditure is some $22 \%$ lower than the corresponding actual. This being the least demanding scenario, since it involves mutual disarmament policies from both the allies and Turkey, does not require expensive, property resource tactics to face an arms race. It is considered, therefore, reasonable that it points towards human resources as the least costly solution. Cyprus, on the other hand, seems to be indifferent in this case, between shifting to property or human resources, with the corresponding average deviations being of the order of about $11 \%$. Despite this "preference" towards human resources in the context of a mutual disarmament scenario, it appears that the relative security is best attained when emphasis is given to property resources, an expensive but efficient and competitive strategy.

\subsection{A Variable Weight Scheme}

The optimal control algorithm we have used allows for the option of expressing the emphasis placed on certain variables not only by means of a specific target value selection but, in addition, by increasing the weight assigned to the deviation of the variable requiring emphasis from its target value. We have thus decided to try this alternative by assigning a double weight to the variables representing the Greek and Cypriot population in order to indicate our emphasis on human resources. Preponderance of property resources, on the other hand, is demonstrated by a double weight on the GDP variable of the two allies.

It is interesting to see that the optimal values for the GDP share of the Greek and Cypriot defence expenditure are somewhat higher compared to those obtained by expressing emphasis via target selection, without, however, reaching the actual defence expenditure figures attained on certain occasions in the past. It is important to point out, therefore, that the picture concerning optimal defence expenditure remains broadly the same in this experiment as well, despite the fact that the optimal values obtained on the basis of the variable weighting scheme are less restrictive compared to those under the fixed weighting scheme. One may thus simply argue that according to the variable weighting scheme the peace dividend approximated by the differences between the optimal and the actual defence expenditure figures for the two allies appears to be somewhat less costly. It is much more important to point out that in both the fixed and the variable weighting schemes the major problem for the two allies, as this is revealed through the "reference" strategy, is the leading role of Turkey in this arms race. This role is always underlined since the intentions of Turkey to escalate or reduce its defence expenditure seem to dictate the corresponding moves to Greece and Cyprus in all cases.

\footnotetext{
${ }^{10}$ In the case of Cyprus, such peak optimal values are influenced by the only major revision of the defence procurement programme during the period under consideration which involved the purchase of a considerable number of Exocet and Aspide missiles as well as that of a large number of G3 rifles to replace the National Guard weapons, sometime during 1992.
} 
The results of the constrained optimisation procedure for both the fixed and the variable weighting schemes, as well as the reasons explaining the different performance of the algorithm in both cases are found in the Appendix.

\section{CONCLUSIONS}

The analysis presented above leads to the following interesting conclusions:

1. Both the Greek and the Cypriot economies are compelled to devote a substantial percentage of their GDP to defence expenditure, about twice as high as the corresponding GDP share in most EU or NATO countries, in the context of all scenarios and strategies tested. This is a burdensome policy option for the two allies given that their economies can only allow about half or, at most, two thirds their actual spending as the optimisation algorithm indicates. Their actual defence expenditure figures, therefore, can be considered as reflecting their preferred positions taking into consideration, in addition to the budget constraint, geopolitical and strategic ones that do not enter our constraints structure. One may, thus, argue that this excessive expenditure measures the costs suffered by the alliance members due to the Greek-Turkish arms race and can be taken to approximate the peace dividend involved. An immediate consequence of excessive defence expenditure is that the relative security coefficient describing the alliance security status vs. Turkey is much higher compared to its optimal values.

2. The optimal values proposed by the algorithm are exclusively determined by the policy followed by Turkey, irrespective of the reaction on the part of Greece and Cyprus. This is a finding that confirms the leading role of Turkey in this arms race and supports the conclusions of earlier work on this issue pointing out that Turkey possesses a weapon of momentous importance in its conflict against Greece and Cyprus, namely that of financial warfare which may lead the economies of its adversaries to their limits.

3. Placing emphasis on capital resources seems to yield optimal values which are closer to the actual ones. This finding leads to the conclusion that preponderance of property resources over human resources, a feature of modern warfare philosophy, may be justified given that it yields optimal values which are, in most cases, closer to those actually attained, indicating an expensive, however desirable policy, to the extent that the high actual GDP shares of defence expenditure are considered necessary.

\section{Acknowledgments}

We are indebted to Professor Keith Hartley and two anonymous referees for their constructive comments. Thanks are also due to Mrs. Helen Gazopoulou of the Bank of Greece and Miss Helena Laskari of the University of Patras for valuable assistance.

\section{References}

Andreou, A. S. and Zombanakis, G. A. (2000). Financial versus human resources in the Greek-Turkish arms race. A forecasting investigation using artificial neural networks. Defence and Peace Economics, 11(4), 403-426.

Andreou, A. S. and Zombanakis, G. A. (2001). A neural network measurement of relative military security: The case of Greece and Cyprus. Defence and Peace Economics, 12(4), 303-324.

Antonakis, N. (1996). Military expenditure and economic growth in less developed countries. Economia Internazionale , 49(3), 329-346.

Antonakis, N. (1997). Military expenditure and economic growth in Greece. Journal of Peace Research, 34(1), 89-100. 
Balfousias, A. and Stavrinos, V. G. (1996). The Greek military sector and macroeconomic effects of military spending in Greece. In: Gleditsch, N. P., Bjerkholt, O., Cappelen, A., Smith, R. P. and Dunne, J. P. (Eds.), The Peace Dividend. North Holland.

Benoit, E. (1978). Growth and defence in developing countries. Economic Development and Cultural Change, 26(2), 271-280.

Bruce, N. (1990). Defence expenditures by countries in allied and adversarial relationships. Defence Economics, 1(3), 179-195.

Buck, D., Hartley, K. and Hooper, N. (1993). Defence research and development, crowding out and the peace dividend. Defence Economics, 4, 161-178.

Chan, S. (1985). The impact of defense spending on economic performance: A survey of evidence and problems. Orbis, 29(2), 403-434.

Chaw G. C. (1975). Analysis and Control of Dynamic Economic Systems, Wiley.

Deger, S. (1986). Military Expenditure in Third World Countries. The Economic Effects. Routledge, London.

Ehrlich, I. and Lui, F. (1997). The problem of population and growth: a review of the literature from Malthus to contemporary models of endogenous population and endogenous growth. Journal of Economic Dynamics and Control, 21(1), 205-242.

Goertz, G. and Diehl, P. F. (1986). Measuring military allocations: a comparison of different approaches. Journal of Conflict Resolution, 30, 553-581.

Greek Ministry of Defence (2000). The White Book. Athens.

Hartley, K. and Hooper, N. (1990). The Economics of Defence, Disarmament, and Peace: An Annotated Bibliography. Elgar, Aldershot \& Brookfield, VT.

Hartley, K. and Sandler, T. (1995). The Economics of Defence. Cambridge University Press, UK.

Hartley, K. and Sandler. T. (Eds.) (1990). The Economics of Defence Spending: An International Survey. Routledge, London.

Herrera, R. (1994). Statistics on Military Expenditure in Developing Countries: Concepts, Methodological Problems and Sources. OECD, Paris.

Isard, W. and Anderton, C. H. (1992). Survey of the peace economics literature. In: Isard, W. and Anderton, C. H. (Eds.), Economics of Arms Reduction and the Peace Process: Contributions from Peace Economics and Peace Science. Elsevier/North Holland, Amsterdam, pp. 1-55.

Klein, L. R., Fu-chen Lo and McKibbin, W. (Eds.) (1995). Arms Reduction: Economic Implications in the Post-Cold War Era. United Nations University Press, Tokyo.

Kollias, C. (1994). The economic effects of defence spending in Greece 1963-1990. Spoudai, 44(3-4), 114-130.

Kollias, C. (1995). Preliminary findings on the economic effects of Greek military expenditure. Applied Economics Letters, 2(1), 16-18.

Kollias, C. (1996). The Greek-Turkish conflict and Greek military expenditure 1960-1992. Journal of Peace Research, 33(2), 217-228.

Kollias, C. (1997). Defence spending and growth in Turkey 1954-1993: A causal analysis. Defence and Peace Economics, 8, 189-204.

Kollias, C. and Makrydakis, S. (1997). Is there a Greek-Turkish arms race? Evidence from cointegration and casuality tests. Defence and Peace Economics, 8, 355-379.

Levy A. (1992). Economic Dynamics: Applications of Difference Equations, Differential Equations and Optimal Control, Avebury.

Looney, R. E. (1994). The economics of third world defence expenditures. In: Contemporary Studies in Economic and Financial Analysis, Vol. 72, JAI Press.

Majeski, S. J. (1984). Arms races as iterated prisoner's dilemma games. Mathematical Social Sciences, 7, $253-266$.

Mintz, A. and Stevenson, R. T. (1995). Defense expenditures, economic growth, and the "Peace Dividend": A longitudinal analysis of 103 countries. Journal of Conflict Resolution, 39(2), 283-305.

Ozmucur, S. (1996). The peace dividend in Turkey. In: Gleditsch, N. P., Bjerkholt, O., Cappelen, A., Smith, R. P. and Dunne, J. P. (Eds.), The Peace Dividend, North Holland.

Parsopoulos, K. E., Plagianakos, V. P., Magoulas, G. D. and Vrahatis, M. N. (2002). Objective function "stretching" to alleviate convergence to local minima. Nonlinear Analysis, T.M.A. (forthcoming).

Parsopoulos, K. E. and Vrahatis M. N. (2001). Modification of the particle swarm optimizer for locating all the global minima. In: Kurkova, V. et al., Artificial Neural Nets and Genetic Algorithms. Springer-Verlag, Wien, pp. 324-327

Pivetti, M. (1992). Military expenditure as a burden on growth, an underconsumptionist critique. Cambridge Journal of Economics, 16(4), 373-384.

Renner, M. (Ed.) (1992). Economic Adjustment after the Cold War: Strategies for Conversion. United Nations Institute for Disarmament Research.

Stavrinos, V. G. and Zombanakis, G. A. (1998). The vicious cycle of the foreign military debt. European Research Studies, 1(1), 5-26.

Vrahatis, M. N., Androulakis, G. S., Lambrinos, J. N. and Magoulas, G. D. (2000). A class of gradient unconstrained minimisation algorithms with adaptive stepsize. Journal of Computational and Applied Mathematics, 114, 367-386.

Ward, M. D. (1991). Military spending in India. Defence Economics, 3(1), 41-63.

Ward, M. D., Davis, D. R. and Lofdahl, C. (1995). A century of tradeoffs: Defense and growth in Japan and the United States. International Studies Quarterly, 39(1), 27-50.

Zombanakis, G. A. (1998). Is the Greek exporters' price policy asymmetric? Greek Economic Review, 19(1). 


\section{APPENDIX I: The Algorithm}

The technique we employ for solving the Optimal Control problem, is an Interior Penalty Function Method, with Steepest Descent and Armijo Line Search. This has been used for the minimization phase as follows:

$$
\Phi\left(x, r_{k}\right)=f(x)-r_{k} \sum_{j=1}^{m} \frac{1}{g_{j}(x)},
$$

where $f(x)$ is the sum of squared differences between the variables and their corresponding target values (i.e. the original objective function ), $g_{j}(x), j=1, \ldots, m$, are the constraints of the proposed model, and $r_{k}$ is the penalty parameter. The repeated application of an unconstrained minimization technique to the function $\Phi(x)$, for a decremented sequence of values of the penalty parameter $r_{k}$, leads to convergence of the corresponding solutions to the solution of the original (constrained) problem, with feasibility standing for each one of the intermediate solutions.

For the unconstrained minimization phase of the algorithm, we employ a widely used method, namely the Steepest Descent technique with Armijo Line Search, allowing the solution an accuracy of $10^{-3}$. As indicated in Appendix II, the maximum number of iterations was set to 500 for all the loops of the algorithm. This maximum number of iterations proved to be enough for obtaining the solution in almost all experiments. In certain cases, however, in which the solution could not be detected after these iterations, re-initialisation to a different feasible starting point was considered as an alternative. The validity of the results obtained has been double-checked using a modification of the Particle Swarm Optimization (PSO) method for locating all the global minima of an objective function (Parsopoulos and Vrahatis, 2001). This involves setting a threshold, beyond which particles of the population bearing lower function values are isolated. Following that, stretching (Parsopoulos et al., 2002) or deflation is performed at this point in order to repel the rest of the swarm (population) from moving toward it. Finally, a local search is performed in its neighborhood, thus detecting a local minimum. Applied to the function $\Phi(x)$, the modified PSO resulted in several local minima of the objective function as well as the global one which, has been compared to the one obtained by the Steepest Descent algorithm. The main aspects of this algorithm are shown in Appendix III.

\section{APPENDIX II: Interior Penalty Function Method with Steepest Descent and Armijo Line Search}

Step 1

Set initial values:

$r_{0}=10$ (Penalty term's initial value),

stop_crit 1, stop_crit $2=0$ (stopping criteria),

iter 1, iter $2=0$ (iteration counters),

MaxIt $=500$ (maximum iterations),

$x_{0}$ (initial feasible, randomly taken, approximation of the solution)

$x_{\text {last }}=x_{0}$ (auxiliary parameter)

$x_{\text {old }}=x_{0}$ (auxiliary parameter) 
$r=r_{0}$ (penalty term variable)

$a c c=10^{-3}$ (desired accuracy)

$h_{0}=1$ (Initial step for the minimization phase)

Step 2

WHILE (stop_crit $1=0)$ AND (iter $1<$ MaxIt) DO

Step 2.1

Set iter $1=$ iter $1+1$, iter $2=0$.

Step 2.2

(* Starting Gradient Descent phase of the algorithm *)

WHILE (stop_crit2 $=0)$ AND (iter $2<$ MaxIt) DO

Step 2.2.1

Set $h=h_{0}$, iter $2=$ iter $2+1$ and $x_{\text {new }}=x_{\text {old }}-h \nabla \Phi\left(x_{\text {old }}, r\right)$.

Step 2.2.2

(* Perform Armijo Line Search to find the optimal step size *)

WHILE $\left(\Phi\left(x_{\text {new }}, r\right)-\Phi\left(x_{\text {old }}, r\right)>-0.5 \mathrm{~h}\left\|\nabla \Phi\left(x_{\text {old }}, r\right)\right\|^{2}\right)$ DO

Set $h=0.5 \mathrm{~h}$.

Re-calculate $x_{\text {new }}=x_{\text {old }}-h \nabla \Phi\left(x_{\text {old }}, r\right)$.

END DO (* End of Armijo Line Search *)

Step 2.2.3

IF $\left\|\nabla \Phi\left(x_{\text {new }}, r\right)\right\| \leq$ acc THEN

stop_crit $2=1$

ELSE

$x_{\text {old }}=x_{\text {new }}$

END IF

END WHILE (* End of Gradient Descent phase *)

Step 2.3

IF $\left\|x_{\text {new }}-x_{\text {last }}\right\|_{\infty} \leq$ acc THEN

ELSE stop_crit $1=1$

$r=0.1 \mathrm{r}$

$x_{\text {last }}=x_{\text {new }}$

$x_{\text {old }}=x_{\text {new }}$

stop_crit $2=0$

END IF

END WHILE

Step 3

Print the final solution $x_{\text {new }}$ and the rest statistics (total iterations, Armijo iterations etc.).

\section{APPENDIX III: Particle Swarm Optimisation Method}

\section{Step 1}

Set a threshold $\varepsilon>0$ and a number of desired minima, $N$.

Step 2

Initialize randomly the population, velocities and the parameters of PSO. Set the set of found minima, $L=\oslash$.

Step 3

Set the maximum number of iterations, MaxIt, and the counter iter $=0$. 
Step 4

WHILE $\operatorname{card}(L) \neq N$ AND iter $<$ MaxIt DO

Step 4.1

Set iter $=$ iter +1 and update PSO's inertia weight.

Step 4.2

Find the best particle, $x_{\text {best }}$, of the swarm and check its value $\Phi\left(x_{\text {best }}\right)$.

Step 4.3

IF $\Phi\left(x_{\text {best }}\right) \leq \varepsilon$ THEN

Isolate $x_{\text {best }}$ and perform local search around it and add the corresponding solution to $L$.

Add a new particle, randomly chosen, into the swarm.

Apply Deflation at $x_{\text {best }}$ by substituting the function $\Phi(x)$ with $\left(\Phi(x) /\left\|x-x_{\text {best }}\right\|\right)$ or apply Stretching by substituting $\Phi(x)$ with $H(x)=G(x)+\left(\gamma_{2} / 2\right)\left(\left(\operatorname{sign}\left(\Phi(x)-\Phi\left(x_{\text {best }}\right)\right)\right.\right.$ $\left.+1) /\left(\tanh \left(\mu\left(G(x)-G\left(x_{\text {best }}\right)\right)\right)\right)\right), \quad$ where $\quad G(x)=\Phi(x)+\left(\gamma_{1} / 2\right)\left\|x-x_{\text {best }}\right\|(\operatorname{sign}(\Phi(x)$ $\left.\left.-\Phi\left(x_{\text {best }}\right)\right)+1\right)$ and $\gamma_{1}=10,000, \gamma_{2}=1, \mu=10^{-10}$.

END IF

END WHILE

\section{Step 5}

Print all elements of $L$ and other desired parameters.

Thus, the solutions were verified and then used for conclusions extraction.

APPENDIX IV (A): Model Equations for Greece (t-values)

\begin{tabular}{|c|c|c|c|}
\hline & Eq. $9(G G D P)$ & Eq. $10(G D E F)$ & Eq. 11 (GPOP) \\
\hline $\mathrm{C}$ & $0.022(3.281)$ & $-0.029(-2.553)$ & $0.001(1.371)$ \\
\hline GNDEF & & $-4.872(-17.598)$ & $0.012(1.837)$ \\
\hline $\operatorname{GNDEF}(-1)$ & $0.100(1.931)$ & & \\
\hline GTIS & $0.235(6.350)$ & & \\
\hline $\operatorname{GBOP}(-1)$ & & $-0.295(-4.859)$ & \\
\hline $\operatorname{GBOP}(-4)$ & $-0.056(-1.878)$ & & \\
\hline DRDL & $-0.062(-1.635)$ & $0.547(8.289)$ & \\
\hline GGDP & & & $0.026(2.286)$ \\
\hline $\operatorname{GGDP}(-1)$ & $0.476(4.869)$ & & \\
\hline $\operatorname{GGDP}(-2)$ & & $0.354(2.102)$ & \\
\hline $\operatorname{GCPI}(-2)$ & & & $-0.0003(-4.927)$ \\
\hline $\mathrm{RS}(-1)$ & & $-0.010(-2.327)$ & \\
\hline $\operatorname{GDEF}(-3)$ & & & $-0.005(-2.001)$ \\
\hline $\operatorname{GPOP}(-1)$ & & & $0.635(6.606)$ \\
\hline TDEF & & $0.112(2.197)$ & \\
\hline $\operatorname{RES}(-1)$ & $-0.048(-1.984)$ & $-0.147(-1.904)$ & $-0.113(-3.054)$ \\
\hline DGGDP & $-0.047(-5.416)$ & & \\
\hline DDIC & $0.048(5.994)$ & & \\
\hline DGDEF & & $0.086(9.881)$ & \\
\hline DGDEMO & & & $0.006(5.547)$ \\
\hline
\end{tabular}


APPENDIX IV (B): Model Equations for Cyprus (t-values)

\begin{tabular}{lccc}
\hline & $E q .12(C G D P)$ & $E q .13(C D E F)$ & $E q .14(C P O P)$ \\
\hline C & $0.052(9.331)$ & $0.024(1.521)$ & $-0.004(-0.614)$ \\
CNDEF & $0.227(2.953)$ & $-16.595(-26.348)$ & $0.055(1.889)$ \\
CNDEF(-4) & & & \\
CBOP & $-0.515(-6.520)$ & $-0.367(-2.037)$ & \\
CBOP(-1) & & $-0.455(-2.578)$ & \\
DLCP & $0.250(3.189)$ & $0.372(2.197)$ & $0.065(1.823)$ \\
CGDP & & $-0.014(-1.538)$ & \\
CGDP(-2) & & & \\
CGDP(-3) & & $0.016(-4.026)$ \\
CCPI & & $-0.704(-5.442)$ & $-0.382(-8.645)$ \\
RS(-2) & & & $0.031(5.275)$ \\
CDEF(-3) & & & \\
CPOP(-1) & & $0.210(8.222)$ & $-0.118(-10.175)$ \\
TDEF & $0.164(-7.383)$ & & $0.004(8.886)$ \\
RES(-1) & $0.130(10.071)$ & & \\
DCGDP & & & \\
DCINV & & & \\
DCDEF & & & \\
DCDEMO & & & \\
TIME & & & \\
\hline
\end{tabular}

\section{APPENDIX IV (C): Equation Diagnostics and A.D.F. Values for the Residuals of their Long-run Versions}

\begin{tabular}{lcccccc}
\hline Code name & $R^{2}$ & D.W. & S.E. & A.D.F. & J-B & Arch F(Pr) \\
\hline Eq. 9 (GGDP) & 0.88 & 2.39 & 0.016 & -2.84 & 0.77 & $0.09(0.76)$ \\
Eq. 10 (GDEF) & 0.98 & 1.87 & 0.025 & -2.59 & 0.66 & $0.27(0.60)$ \\
Eq. 11 (GPOP) & 0.81 & 1.86 & 0.002 & -3.33 & 1.54 & $0.64(0.42)$ \\
Eq. 12 (CGDP) & 0.84 & 2.02 & 0.033 & -2.76 & 1.70 & $0.32(0.57)$ \\
Eq. 13 (CDEF) & 0.97 & 1.60 & 0.060 & -3.98 & 0.04 & $0.87(0.35)$ \\
Eq. 14 (CPOP) & 0.91 & 1.41 & 0.012 & $-2.06^{*}$ & 1.17 & $0.30(0.58)$ \\
\hline
\end{tabular}

*All A.D.F. tests indicate that the series are $\mathrm{I}(0)$ at a $1 \%$ level except Eq. 14 which describes the behaviour of the Cypriot population in the case of which is $\mathrm{I}(0)$ at a $5 \%$ level. The J-B (Jarque-Bera statistic) show that the errors are normally distributed while the $\mathrm{ARCH}$ figures for autoregressive conditional heteroskedasticity are not significant.

\section{APPENDIX V: Fixed Versus Variable Weighting Scheme}

Multiplying a term of the quadratic penalty function with a weight $w>1$, steepens the function at the direction of the corresponding variables, without, however, changing the nonlinear constraints implied by the model. This may result in optimal values that lie closer to the target values, for these variables. The same effect may be achieved, if the target values are properly increased. 
Let $x_{i}$ be the variable under consideration. Then, the first partial derivative of the penalty function $\Phi\left(x, r_{k}\right)$ in $x_{i}$ is defined as:

$$
\frac{\partial \Phi}{\partial x_{i}}=\frac{\partial f}{\partial x_{i}}-\frac{\partial}{\partial x_{i}}\left(r_{k} \sum_{j=1}^{m} \frac{1}{g_{j}}\right)
$$

where $f(x)=\sum_{j=1}^{m}\left(x_{j}-t_{j}\right)^{2}$ is the sum of the squared differences of the variables and their corresponding target values. Thus, after the multiplication with $w$ :

$$
\frac{\partial f}{\partial x_{i}}=2 w\left(x_{i}-t_{i}\right)
$$

If, instead of multiplying by $w$, an offset $a$ is added to the target value of $x_{i}$, then:

$$
\frac{\partial f}{\partial x_{i}}=2\left(x_{i}-\left(t_{i}+a\right)\right)
$$

These two forms of the first partial derivative of $f$, are equal if $x_{i}=t_{i}-(a / w-1)$. If this relation does not hold, then the effect may be different in each case, depending on the constraints. This explains the variation in the optimal values, depending on the weight $w$ and the offset $a$ used in each case.

\begin{tabular}{|c|c|c|c|c|c|c|}
\hline \multirow[b]{3}{*}{ Scenarios } & \multicolumn{6}{|c|}{ Strategies } \\
\hline & \multicolumn{2}{|c|}{ Human res. } & \multicolumn{2}{|c|}{ Property res. } & \multicolumn{2}{|c|}{ Reference* } \\
\hline & Fixed $w$. & Vble $w$. & Fixed $w$. & Vble $w$. & Fixed $w$. & Vble w. \\
\hline All escalate & $\begin{array}{l}2.2-6.3 \\
3.5\end{array}$ & $\begin{array}{c}3.8-4.9 \\
4.3\end{array}$ & $\begin{array}{c}1.4-5.9 \\
3.3\end{array}$ & $\begin{array}{c}3.4-4.8 \\
4.3\end{array}$ & $\begin{array}{c}1.9-6.5 \\
3.6\end{array}$ & $\begin{array}{c}3.8-5.2 \\
4.5\end{array}$ \\
\hline $\begin{array}{l}\text { GR \& CY escalate } \\
\text { TR reduces }\end{array}$ & $\begin{array}{c}1.4-5.8 \\
3.4\end{array}$ & $\begin{array}{c}3.6-4.7 \\
4.2\end{array}$ & $\begin{array}{c}1.5-6.3 \\
3.4\end{array}$ & $\begin{array}{c}3.9-4.7 \\
4.2\end{array}$ & $\begin{array}{c}1.5-6.1 \\
3.4\end{array}$ & $\begin{array}{c}3.4-4.7 \\
4.1\end{array}$ \\
\hline $\begin{array}{l}\text { GR \& CY reduce } \\
\text { TR escalates }\end{array}$ & $\begin{array}{c}1.8-5.7 \\
3.4\end{array}$ & $\begin{array}{c}3.4-5.0 \\
4.2\end{array}$ & $\begin{array}{c}1.6-6.1 \\
3.5\end{array}$ & $\begin{array}{c}3.7-4.6 \\
4.3\end{array}$ & $\begin{array}{c}1.9-6.5 \\
3.6\end{array}$ & $\begin{array}{c}3.8-5.2 \\
4.5\end{array}$ \\
\hline All reduce & $\begin{array}{c}2.3-6.4 \\
3.4\end{array}$ & $\begin{array}{c}3.9-4.8 \\
4.2\end{array}$ & $\begin{array}{c}1.6-6.1 \\
3.4\end{array}$ & $\begin{array}{c}3.6-4.8 \\
4.7\end{array}$ & $\begin{array}{c}1.5-6.1 \\
3.4\end{array}$ & $\begin{array}{c}3.4-4.7 \\
4.1\end{array}$ \\
\hline
\end{tabular}

\section{APPENDIX VI (A): Constrained Optimisation Results: Optimal Defence Expenditure/GDP for Greece (Extreme Values and Mean)}

*The Reference strategy is characterised by complete absence of any form of emphasis on either of the two resource categories. 


\section{APPENDIX VI (B): Constrained Optimisation Results: Optimal Defence Expendi- ture/GDP for Cyprus (Extreme Values and Mean)}

\begin{tabular}{|c|c|c|c|c|c|c|}
\hline \multirow[b]{3}{*}{ Scenarios } & \multicolumn{6}{|c|}{ Strategies } \\
\hline & \multicolumn{2}{|c|}{ Human res. } & \multicolumn{2}{|c|}{ Property res. } & \multicolumn{2}{|c|}{ Reference* } \\
\hline & Fixed $w$. & Vble $w$. & Fixed $w$ & Vble $w$ & Fixed $w$. & Vble w. \\
\hline All escalate & $\begin{array}{c}1.8-5.7 \\
3.6\end{array}$ & $\begin{array}{c}3.5-4.3 \\
4.0\end{array}$ & $\begin{array}{c}2.1-5.8 \\
3.6\end{array}$ & $\begin{array}{c}3.5-4.6 \\
4.3\end{array}$ & $\begin{array}{c}1.8-6.1 \\
3.6\end{array}$ & $\begin{array}{c}3.5-5.0 \\
4.1\end{array}$ \\
\hline $\begin{array}{l}\text { GR \& CY escalate } \\
\text { TR reduces }\end{array}$ & $\begin{array}{c}1.1-5.4 \\
3.6\end{array}$ & $\begin{array}{c}3.3-4.2 \\
3.8\end{array}$ & $\begin{array}{l}1.7-5.8 \\
3.6\end{array}$ & $\begin{array}{c}4.0-4.5 \\
4.2\end{array}$ & $\begin{array}{c}1.4-5.6 \\
3.5\end{array}$ & $\begin{array}{c}3.1-4.5 \\
3.8\end{array}$ \\
\hline $\begin{array}{c}\text { GR \& CY reduce } \\
\text { TR escalates }\end{array}$ & $\begin{array}{c}1.6-6.1 \\
3.8\end{array}$ & $\begin{array}{c}3.1-4.5 \\
3.5\end{array}$ & $\begin{array}{l}2.1-5.5 \\
3.7\end{array}$ & $\begin{array}{c}3.8-4.5 \\
4.1\end{array}$ & $\begin{array}{c}1.8-6.1 \\
3.6\end{array}$ & $\begin{array}{c}3.5-5.0 \\
4.1\end{array}$ \\
\hline All reduce & $\begin{array}{c}1.5-5.9 \\
3.6\end{array}$ & $\begin{array}{c}3.6-4.3 \\
4.0\end{array}$ & $\begin{array}{c}1.7-5.8 \\
3.6\end{array}$ & $\begin{array}{c}3.7-4.6 \\
4.0\end{array}$ & $\begin{array}{l}1.4-5.6 \\
3.5\end{array}$ & $\begin{array}{c}3.1-4.5 \\
3.8\end{array}$ \\
\hline
\end{tabular}

*The Reference strategy is characterised by complete absence of any form of emphasis on either of the two resource categories.

\section{APPENDIX VII: Variables and Data Sources}

\begin{tabular}{|c|c|c|}
\hline Code & Data series & Source \\
\hline GGDP & GDP of Greece, Constant Prices & Greek National Accounts \\
\hline CGDP & GDP of Cyprus, Constant Prices & Cypriot National Accounts \\
\hline GTIS & $\begin{array}{l}\text { Greek Government Total Investment } \\
\text { Expenditure, (share of GDP) }\end{array}$ & Greek National Accounts \\
\hline GDEF & $\begin{array}{l}\text { Defence Expenditure of Greece } \\
\text { (share of GDP) }\end{array}$ & SIPRI \\
\hline $\mathrm{CDEF}$ & $\begin{array}{l}\text { Defence Expenditure of Cyprus } \\
\text { (share of GDP) }\end{array}$ & SIPRI \\
\hline TDEF & $\begin{array}{l}\text { Defence Expenditure of Turkey } \\
\text { (share of GDP) }\end{array}$ & SIPRI \\
\hline GNDEF & $\begin{array}{l}\text { Non-Defence Government Expendi- } \\
\text { ture of Greece (share of GDP) }\end{array}$ & Greek National Accounts \\
\hline CNDEF & $\begin{array}{l}\text { Non-Defence Government Expendi- } \\
\text { ture of Cyprus (share of GDP) }\end{array}$ & Cypriot National Accounts \\
\hline GBOP & $\begin{array}{l}\text { Greek Balance-of-Payments Deficit } \\
\text { (share of GDP) }\end{array}$ & Greek National Accounts \\
\hline $\mathrm{CBOP}$ & $\begin{array}{l}\text { Cypriot Balance-of-Payments Deficit } \\
\text { (share of GDP) }\end{array}$ & Cypriot National Accounts \\
\hline DRDL & Drachma/U.S. Dollar Exchange Rate & Bank of Greece \\
\hline DLCP & $\begin{array}{l}\text { U.S. Dollar/Cypriot Pound Exchange } \\
\text { Rate }\end{array}$ & I.F.S. \\
\hline GCPI & Greek Consumer Price Index & I.F.S. \\
\hline CCPI & Cypriot Consumer Price Index & I.F.S. \\
\hline GPOP & Greek Population Growth & I.F.S. \\
\hline CPOP & Cypriot Population Growth & I.F.S. \\
\hline
\end{tabular}

